\title{
Erratum to: Turbulence-particle interactions under surface gravity waves
}

\author{
Mostafa Bakhoday Paskyabi ${ }^{1}$
}

Published online: 6 February 2017

(C) Springer-Verlag Berlin Heidelberg 2017

Erratum to: Ocean Dynamics (2016) 66:1429-1448

DOI 10.1007/s10236-016-0989-0

The article "Turbulence-particle interactions under surface gravity waves", written by "Mostafa Bakhoday Paskyabi", was originally published Online First without open access. After publication in volume 66, issue 11, pages 1429-1448 the author decided to opt for Open Choice and to make the article an open access publication. Therefore, the copyright of the article has been changed to (C) The Author(s) 2016 and the article is forthwith distributed under the terms of the Creative Commons Attribution 4.0 International License (http:// creativecommons.org/licenses/by/4.0/), which permits use, duplication, adaptation, distribution and reproduction in any medium or format, as long as you give appropriate credit to the original author(s) and the source, provide a link to the Creative Commons license, and indicate if changes were made.

The online version of the original article can be found at $\mathrm{http} / / \mathrm{dx}$.doi.org/ 10.1007/s10236-016-0989-0.

Mostafa Bakhoday Paskyabi

Mostafa.Bakhoday@uib.no

1 Geophysical Institute, University of Bergen, and Bjerknes Center for Climate Research, Bergen, Norway 